\title{
The non-existence of institutional facts
}

\author{
Friedrich Christoph Dörge ${ }^{1} \cdot$ Matthias Holweger $^{2}$ (D)
}

Received: 10 February 2020 / Accepted: 22 December 2020 / Published online: 10 February 2021

(c) The Author(s) 2021

\begin{abstract}
That certain paper bills have monetary value, that Vladimir Putin is the president of Russia, and that Prince Philip is the husband of Queen Elizabeth II: such facts are commonly called 'institutional facts' (IFF). IFF are, by definition, facts that exist by virtue of collective recognition (where collective recognition can be direct or indirect). The standard view or tacit belief is that such facts really exist. In this paper we argue, however, that they really do not-they really are just well-established illusions. We confront realism about IFF with six criteria of existence, three established and three less so but highly intuitive. We argue that they all tell against the existence of IFF. An obvious objection to IFF non-realism is that since people's behaviour clearly reflects the existence of IFF, denying their existence leaves an explanatory gap. We reject this argument by introducing a variant of the so-called 'Thomas Theorem,' which says that when people collectively recognize a fact as existing, they largely behave accordingly, regardless of whether that fact really exists or not.
\end{abstract}

Keywords Institutional fact · Existence $\cdot$ Existence criteria $\cdot$ Ontological projection · Collective recognition $\cdot$ Thomas theorem

\section{Introduction}

That the universe is expanding, that $\mathrm{H}_{2} \mathrm{O}$ molecules contain hydrogen and oxygen atoms, and that men do not become pregnant: such facts are commonly referred to as 'brute' (or 'natural') facts. Brute facts are the subject of the natural sciences; and they are supposed to exist independently of whether they are represented as existing

Matthias Holweger

matthias@uli-holweger.de

Friedrich Christoph Dörge

chris.doerge@hotmail.de

1 Philosophy Department, Eberhard Karls Universität Tübingen, Französische Allee 3, 72072 Tübingen, Germany

2 Philosophy Department, Eberhard Karls Universität Tübingen, Sigwartstraße 15, 72076 Tübingen, Germany 
or otherwise accepted or recognized. But apparently our world is also home to facts of a completely different kind, such as the fact that Vladimir Putin is the president of Russia, the fact that Germany won the 2014 World Cup final, the fact that Prince Philip is the husband of Queen Elizabeth II, or the fact that French citizens have the right to form associations.

In the analytic-philosophical debate, facts ${ }^{1}$ of the latter kind are commonly called 'institutional facts' $\left(\mathrm{IFF}^{2}\right)$. As that name already indicates, the existence of these facts is usually led back to so-called 'institutions'. Thus, Elizabeth Anscombe, who seems first to have applied the term 'institutional' in written form to such facts, suggested that they are instantiated 'only in the context of our institutions' (1958, p. 70). And John Searle, who then established the term 'institutional fact', defined them quite explicitly as facts that 'require human institutions for their existence' $(1995, \mathrm{p}$. 2; cf. 2010a, pp. 10-11).

Established though this reference to 'institutions' is, it brings in the danger of confusion. One problem is that the term 'institution' is here apparently not used in its everyday sense (in which it refers to things such as the police, or urban administration), but in a peculiar, technical sense. ${ }^{3}$ Another, more serious problem is that Searle's original definition of IFF with reference to 'institutions' (in this technical sense) seems to be too narrow: it does not seem to cover the full range of phenomena for which the term was originally introduced. ${ }^{4}$ Fortunately, a definition largely capturing the predominant current use of this term does not seem to require any recourse to the problematic notion of an 'institution' anyway, for it seems largely accepted in the debate on IFF that the (decisive) defining property which has been targeted by the notion of an 'institution' is just that IFF exist by virtue of the collective recognition $(\mathrm{CR})$ of their existence, ${ }^{5}$ in a sense of 'collective recognition'

\footnotetext{
1 In order to avoid awkward phrases and not to beg the question, we shall use realist jargon throughout in this paper. Thus, for example, although we do not believe that Vladimir Putin's being the president of Russia actually is a fact, we shall nevertheless refer to it as a 'fact'.

${ }^{2}$ We abbreviate the singular form with 'IF', and the plural form with 'IFF'.

3 Searle uses it to refer to what he calls 'systems of constitutive rules', that is, rules existing by virtue of collective recognition that make possible or constitute new kinds of entities (cf. 1964, p. 55, 1995, pp. 27-28, 2007a, p. 11, 2010a, p. 10), typically taking the form $X$ counts as $Y$ (in C) (cf. 2005, p. 10, 1995, p. 114, 2010a, p. 10). Thus, the reason why Searle chose the term 'institutional' to characterise these facts is probably that he originally took the existence of these facts to go back to systems of constitutive rules (hence, to 'institutions', in the particular sense he assigns to this word).

4 As Searle puts it: 'sometimes we can just create an institutional fact [...] without a constitutive rule' (2012, p. 31), 'a tribe might simply count a certain person as their leader [...] though there is no existing institution' (2010a, p. 19; cf. ibid., pp. 21, 94, 96, 2007c, p. 91, 2017). After observations like these, Searle seems to have faced himself with the question of whether or not he should stick to this term: 'I am not sure', he says in a more recent paper, 'if everybody would agree that we ought to call such facts Institutional Facts' (2014, p. 18). He chose to retain it (apparently because the term was already established) and implicitly redefine it: 'I get a more elegant result if I include all of these things as Institutional Facts' (ibid.).

5 That this is, and has always been, supposed to be the decisive defining property of IFF is consistently affirmed, for example, in Searle's writings (cf. 1995, pp. 2, 47, 51, 62-63, 117, 1997, p. 452, 2005, p. 9, 2006 , pp. 53, 58, 2010a, pp. 8, 10, 94, 103, 107, 116, 2010b, pp. 35, 43, 2010c, pp. 228-229, 2012, p. 35, 2014, p. 23).
} 
that will be clarified in a moment. ${ }^{6}$ Thus, the term 'institutional fact' is commonly applied to facts such as the fact that Vladimir Putin is the president of Russia and the fact that Prince Philip is the husband of Queen Elizabeth II essentially because it is commonly assumed that such facts differ from other kinds of facts, most notably brute facts, in that they depend on CR for their existence. We share this assumption and thus think that a definition of 'institutional fact' simply in terms of CR is extensionally adequate ${ }^{7}$ : it seems to pick out quite properly the range of phenomena to which most of the participants in the debate intend to refer when they use this technical term. So we define 'institutional facts' as follows:

\section{Definition of 'institutional fact' $(\text { IF })^{8}$ :}

That the (putative) fact that $p$ is an 'institutional fact' means that $p$ is a fact that exists by virtue of the collective recognition of its existence. ${ }^{9}$

It is important to see, and keep in mind, that the definition just provided determines the limits of our investigation. In this paper we are exclusively concerned with IFF in this sense, which is to say that we are exclusively concerned with the (non-) existence of facts that exist by virtue of the CR of their existence. Moreover, in this paper we are not concerned with another question prominent within social ontology: the question of whether certain facts that are commonly classified as IFF are really 'IFF' (facts that require CR for their existence), or rather something else. ${ }^{10}$ Like a great many of the participants in the relevant debates, we confidently take it for granted in this paper that facts such as the fact that Vladimir Putin is the president of Russia, the fact that Prince Philip is the husband of Queen Elizabeth, the fact that Germany won the 2014 World Cup final 1-0 against Argentina, and so on, are indeed IFF, that is, that they are indeed facts that require CR for their existence. If it turned out, for example (contrary to what we and many others would presume), that Vladimir Putin does not have to be CR-ed as president of Russia to actually

\footnotetext{
${ }^{6}$ As indicated, we intend to capture what we perceive to be the predominant current use. We do not deny that there are authors who (explicitly or implicitly) define or use the term differently. Moreover, it is not our intention here to criticise other potential uses and definitions; we only want to make clear the sense in which we are using the term.

7 The term 'extensional adequacy' aims at adequacy with respect to the hypothetical extension of the term. (In our view, the term 'institutional fact' has no real extension.)

${ }^{8}$ By thus defining the term without reference to the term 'institution', our current investigation makes no (conscious) contribution to matters of 'institutions' in most of the senses associated with this term. In philosophy, the social sciences and legal studies the term is used in various debates, sometimes in very different senses. Since our investigation is unrelated to most of those uses, we even considered avoiding the term 'institutional facts'. The reason why we finally decided to stick to this term is that in the debate we are addressing, Searle's theory is terminologically predominant. We think that avoiding this term is more likely to create further confusion than to provide more clarity.

9 See Holweger (2020) (ms.) for a defence against considerations to make the definition more complex.-The 'exists by virtue of' formula is used in a non-reductive sense in which ' $x$ exists by virtue of $y$ ' entails that $x$ determines the existence of $y$, but is not identical with $y$. Thus, according to this definition, IFF are not identical with their being collectively recognized as existing.

${ }^{10}$ Works that might be construed as suggesting that such facts are really something else include Mäkelä and Ylikoski (2003), Epstein (2014a, b, 2015), Guala (2014, 2016), Guala and Hindriks (2015), Smit et al. (2014) and Thomasson (2003).
} 
be the president of Russia, this would only mean that this fact turns out to be outside the scope of our investigation, after all. It would not mean that anything was wrong with our arguments against the existence of facts which actually do satisfy our definition. ${ }^{11}$

Let us now turn to the term 'collective recognition'. It is obvious (though rarely noticed) that in the present debate, this and other terms such as 'collective acceptance' are used in technical senses. ${ }^{12}$ As we use the term, CR can take two forms: 'direct' CR and 'indirect' CR. In the case of 'direct' CR, an IF is created by virtue of being collectively represented as existing. When the members of a tribe collectively represent someone as their leader, for example, then this makes it the case that this person is their leader. The notion 'represent as existing' we define partially as follows: If $S$ 'endorsively' thinks of $p$ as existing, or (tacitly) believes that $p$ exists, or presupposes that $p$ exists, then $S$ 'represents' $p$ as existing. These are sufficient conditions. A condition necessary for $\mathrm{S}$ to 'represent $p$ as existing' is that $\mathrm{S}$ have an, as one might call it, 'ontologically endorsive' mental attitude towards $p$. The 'endorsement' involved is supposed to be endorsement of a certain existential status. ${ }^{13}$ Thus, a borderline case such as treating $A$ as $B$ cannot be a case of representing the (putative) fact that $A$ is $B$ as existing unless it involves an ontologically endorsive mental attitude towards the (putative) fact that $\mathrm{A}$ is $\mathrm{B}$.

\section{Definition of 'direct collective recognition' (direct CR):}

That the (putative) fact that $p$ is 'directly collectively recognized' (directly

CR-ed) means that $p$ is collectively represented as existing.

While direct $\mathrm{CR}$ is the simplest case, it fails to exhaust the phenomenon of CR by far. Indeed, most IFF actually go back to 'indirect CR' which, quite simply, amounts to $\mathrm{CR}$ which is not direct. For example, most if not all cases of IFF that Searle leads back to his famous 'constitutive rules' are cases of indirect CR. Here is an example. Imagine that among the townsmen of a city state it is directly CR-ed that the king's nearest male relative is heir apparent, and let us assume that Peter is in fact the king's nearest male relative. Then, given the existence of the rule, Peter is heir apparent. What is special about this case is that the citizens need not collectively 'represent' Peter as heir apparent for him to actually have that status. Even if some ill-intending group favoring someone else manages to conceal Peter's degree of relationship with the king, it would still be an IF that he is (the 'actual' or 'legitimate') heir apparent. Yet in this case, this is not due to direct CR; it is due to (a) the direct CR of something else (that the king's nearest male relative is heir apparent), together with (b) matters of fact (in particular, that Peter is the king's nearest male relative). ${ }^{14}$

\footnotetext{
11 We thank two anonymous reviewers for urging us to clarify this.

12 For example, it is customary to use 'collective recognition' in such a way that 'collective recognition of $p$ ' is entailed by 'collective (tacit) belief that $p$ '. This would not be the case in any ordinary sense of 'recognition'.

13 The qualifying phrase 'ontologically endorsive' is, of course, vague; but this might be a virtue rather than a vice, as different authors have different conceptions of where exactly the boundaries of 'collective recognition' should be drawn.

14 The notion of 'matters of fact' here applied is to be construed widely enough as to include IFF.
} 


\section{Definition of 'indirect collective recognition' (indirect CR):}

That the (putative) fact that $p$ is 'indirectly collectively recognized' (indirectly CR-ed) means that $p$ is collectively recognized, but not by virtue of being collectively represented as existing.

While ' $p$ is indirectly CR-ed' does not entail that $p$ itself is collectively represented as existing, it does entail that something is collectively represented as existing. Indeed, it is a distinguishing feature of IFF that, unlike brute facts, their existence consistently depends on collective representation. This is important for our discussion of 'Ontological Projection' below.

Having defined 'direct CR' and 'indirect CR', the question remains as to how 'collective recognition' in general is to be defined. This is a tricky issue; and since it is of no crucial import for the issues at hand, we shall present our proposal without going into much detail. ${ }^{15}$

\section{Definition of 'collective recognition':}

That the (putative) fact that $p$ is 'collectively recognized' means that $p$ is logically entailed by some content of collective representation (COCR) (or the conjunction of some COCRs), or that there are certain facts such that $p$ is logically entailed by the representation of those facts, together with some COCR (or the conjunction of some COCRs).

In the case of direct CR, $p$ is logically entailed by a particular COCR. For example, if it is directly CR-ed by a certain group that Mary is their leader, then there is some COCR to the effect that Mary is the leader of the group.

In the case of indirect CR, however, $p$ is not logically entailed by a particular COCR; in such a case, there are facts the representation of which logically entails $p$, together with some COCR or the conjunction of some COCRs. In the case of Peter, the heir apparent, it is a fact that Peter is the king's nearest male relative. The fact that Peter is heir apparent is logically entailed by the representation of this fact, together with some COCR, to the effect that the king's nearest male relative is heir apparent.

In the present paper we are concerned with the ontological status of IFF. The standard view (or tacit belief), both inside and outside philosophy, is that IFF really exist. This view we call 'IF Realism':

\section{IF Realism:}

IFF exist.

In this paper, we shall argue for the nonexistence of IFF, and therefore, in our view, for the nonexistence of such things as the value of money, the presidency of Vladimir Putin, and the marriage between Prince Philip and Queen Elizabeth II. We think that such facts are just collective illusions (although obviously very well-established ones).

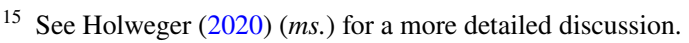


The essential problem we see with IF Realism can be explained with reference to what we call 'Ontological Projection'. We define this as an operation connecting the collective representation of an entity as existing with its real existence. ${ }^{16}$

\section{Definition of 'Ontological Projection':}

'Ontological projection' is the generation of an entity ${ }^{17}$ (or its maintenance in existence $)^{18}$ by virtue of collectively representing it as existing.

Since IFF are (by definition) facts that exist by virtue of being CR-ed as existing, and since CR always involves the generation of something by collectively representing it as existing, the existence of IFF presupposes the assumption that Ontological Projection occurs at least sometimes. We call this the 'Projection Principle'.

\section{The Projection Principle:}

Ontological Projection occurs at least sometimes.

In our view, Ontological Projection never occurs. It is just impossible to generate things or facts just by virtue of representing them as existing.

We shall start our case for the nonexistence of IFF by confronting IF Realism with six criteria of existence-three established and three less so but highly intuitive. We shall argue that IFF violate each of these criteria. Next, we shall focus on Ontological Projection, because it seems to us that considering certain of its characteristics leads to a more thorough grasp of the problems at hand. In particular, we shall see that the problems of Ontological Projection largely reflect the problems we shall encounter in examining IFF. After that, we shall consider a rather common and (at a first glance) very intuitive kind of objection to nonrealism about IFF. The objection is that our behaviour reflects the existence of many IFF (such as the value of money, presidencies and marriages) so consistently that the denial of their existence would appear to be absurd, or at least leave us with a massive explanatory gap. We reject this argument, among other things, by introducing a variant of the so-called 'Thomas Theorem', which roughly says that when people collectively recognize a fact as existing, then they largely behave accordingly, regardless of whether that fact really exists or not.

Recently, some authors expressed doubts about the method of existence criteria. In our view, these doubts largely go back to certain misapprehensions concerning the nature of such criteria and the role they play in ontological investigation. Thus, before starting our case for the nonexistence of IFF let us briefly clarify the nature of these criteria.

\footnotetext{
${ }^{16}$ Here, the term 'operation' is to be understood in a wide sense, covering all kinds of generation, including causation and determination. The same holds for the term 'generate', which is, among other things, intended to cover both causality and 'constitution' (see below Sect. 3.2).

17 The notion of an 'entity', as here used, is wide enough as to cover, among other things, facts.

18 In the following, 'generation of existence' is always meant to include maintenance in existence.
} 


\section{Some remarks on existence criteria}

In our view, the most natural way to deal with questions of existence is to search for, discuss and apply 'criteria of existence'. However, apart from the fact that this method has not yet been established metaontologically in any proper way, it has recently been confronted with fundamental doubts by various authors, who represent such an approach as problematic or even downright misguided (cf., e.g., Azzouni 1998, 2004: Ch. 4, 2010; Raley 2004 (unpublished dissertation); Thomasson 2008, 2015: Ch. 2.5). In our view, these doubts go back to one or the other misapprehension about what existence criteria actually are, and how they are to be used.

As we see it, existence criteria are criteria of existence, i.e., criteria used as means for judging whether certain (kinds of) entities exist or not. For a (kind of) entity to satisfy an existence criterion is to satisfy a condition which is either necessary, or sufficient, or both, for its existence.

Existence criteria are sometimes represented as somehow 'peculiar'. In our view, this is ungrounded. Those who find them peculiar seem to ascribe features to these criteria that they do not necessarily have. Thomasson (2008, p. 73f.), for example, presumes (or at least insinuates) that existence criteria must be completely general, that they must be conditions "for the existence of "anything whatsoever", criteria 'shared across the board for (putative) objects of any kind'. This is an overly narrow construal of such criteria, however. Nothing is wrong with the idea of existence criteria that are restricted to entities of a certain kind (material objects, for instance).

Authors sometimes show a tendency to use the term 'existence criteria' particularly for conditions necessary for existence. There seems to be no inconsistency, however, in using the term as well for conditions (merely) sufficient for existence, or for conditions that are necessary and sufficient for existence. But even if existence criteria are necessarily necessary conditions, it would be premature to think that what we are doing is explicate the notion of 'existence', and that the conditions must therefore be semantically necessary conditions. Indeed, any kind of necessity may be involved. We might, for instance, lead the requirement of spatio-temporal location for material objects back to considerations about the concept 'material'; or we might lead a criterion back to matters of fact, ${ }^{19}$ as when we require existing entities to be composed of certain kinds of minimal elements, according to the findings of our theories.

Finally, from this it follows that the method of existence criteria does not presuppose that we can state the meaning of 'existence', as some might be tempted to think. It may well be (and seems rather likely) that it is impossible to provide an analytic definition of 'existence'. This, of course, does not imply that existence criteria cannot partially clarify the meaning of 'existence' in some or the other way.

\footnotetext{
19 We assume here that inductive reasoning can lead to the statement of necessary conditions. We disregard the question of whether such a procedure would be epistemically justified.
} 
With these (admittedly, cursory) remarks we hope to have at least preliminarily mitigated the view that the method of existence criteria is flawed from the start. ${ }^{20}$ Let us now turn to the examination of IF Realism with reference to this method.

\section{Conflicts between IF realism and existence criteria}

\subsection{IFF and representation-independence}

One of the most traditional and popular existence criteria is the so-called 'MindIndependence' of existence. It is usually characterised by phrases like this:

\section{Mind-Independence:}

Existing entities exist independently of our minds.

Put in such a form, the criterion is ambiguous and possibly misleading. What we aim at by invoking this criterion may be captured by the term 'Representation-Independence':

\section{Representation-Independence:}

Existing entities exist independently of whether they are represented as existing or not.

On this occasion, we use 'representation' in a broad sense in which it covers, among other things, perception, imagination, thinking, belief and recognition. By saying that entities exist 'independently of' whether they are represented or not we mean to imply that (a) the existence of an entity does not entail that it is represented by someone, and (b) that someone's (or some people's) representing it as existing, regardless of how many and who the representing beings are, does not entail that it actually exists. To be sure, the criterion clearly does not entail that representations themselves do not exist. Representations are, in our view, obvious cases of entities that exist independently of whether they are represented as existing or not.

If we accept Representation-Independence as an existence criterion, then we have reason to deny the existence of IFF. To start with, the existence of directly CR-ed IFF will be rejected because these are supposed to exist by virtue of their being collectively represented as existing, which blatantly implies that their existence is not representation-independent. And in the case of indirectly CR-ed IFF, there is also representation-dependency. For if something is an IF, it has to be CR-ed; and that it has to be CR-ed implies that its existence must involve the existence of something that depends on being collectively represented as existing. So, cases of indirectly CR-ed IFF are inconsistent with Representation-Independence, too.

\footnotetext{
${ }^{20}$ Our conception of how to approach questions of existence in terms of existence criteria will be addressed more comprehensively in a subsequent paper.
} 


\subsection{IFF and causal integration}

Next to Mind-Independence, one of the most prominent existence criteria is what may be called the 'Causal Efficacy' of existing entities. Going back to a passage in Plato's Sophist ${ }^{21}$ this criterion has been discussed extensively since then and is advocated by many authors.

\section{Causal Efficacy:}

Existing entities are causally efficacious.

A related criterion, which is less often discussed, but no less plausible, is 'Causal Origination'.

\section{Causal Origination:}

Existing entities are caused.

Combining these two criteria, we obtain what we may call 'Causal Integration'.

\section{Causal Integration:}

Existing entities are both caused and causally efficacious.

Many ontologists, and in particular those who advocate one or the other form of causal determinism, endorse Causal Integration. Yet, IFF do not seem to satisfy this criterion. ${ }^{22}$

Let us start with the paradigmatic case of direct CR. The generation of an entity by its being collectively represented as existing is surely not a case of causation; instead, it is a case of what is commonly called 'constitution'. ${ }^{23}$ The fact that a certain line of stones around a village is a borderline is (supposed to be) constituted by the $\mathrm{CR}$ of this line as a borderline.

Essentially the same is true in cases of indirect CR. Let us consider the case of Peter, who, being the king's closest male relative, is heir apparent by virtue of the

\footnotetext{
${ }^{21}$ See Plato, Sophist, 247d-e.

${ }^{22}$ Obviously, our application of Causal Integration to IFF is cursory and tentative. Thus, for example, we leave untouched the elementary question of whether facts in general are of the right ontological category to be possible subjects of causal integration, as, for example, Searle seems to indicate (cf. 1995, p. 206). According to an influential and quite plausible view, causal integration requires location (cf., e.g., Kim 2005: Ch. 3). Given this, one might argue that facts cannot be causally integrated, as it is impossible for them to have a 'location' in any ordinary sense of the term. We would like to stress that even if such considerations turned out to be correct, this would not mean that it is impossible to find an adequate causal criterion that is specifically tailored to (certain kinds of) facts. For example, a determinist might plausibly require that if Vladimir Putin is the president of Russia, then the corresponding state of Vladimir Putin being the president of Russia be caused. This suggests that a more adequate criterion, applying to such kinds of facts, might be based on a distinction between the facts themselves and certain states that 'correspond to' these facts.

${ }^{23}$ The term 'constitute' is used in different ways. Sometimes, relations like that between $\mathrm{H}_{2} \mathrm{O}$ molecules and water are addressed by the term. In such cases, the notion aims at identity, or extensional equality, under different descriptions. The present sense of 'constitution', by contrast, aims at an operation that involves the generation of something new. An approach that identifies the existence of $p$ with its being CR-ed as existing would be eliminatively reductive. Since eliminative views are not variants of IF Realism, we are not considering them here.
} 
direct CR that the king's nearest male relative is heir apparent. Peter's status is generated by a natural fact only against the background of, or given, the directly CR-ed fact that the king's nearest male relative is heir apparent. Since indirect CR implies the direct CR of something, and since the efficacy of direct CR is inconsistent with Causal Origination, indirect CR is inconsistent with Causal Origination, too. So, in both direct and indirect cases, IFF seem to violate Causal Integration. ${ }^{24}$

\subsection{IFF and spatio-temporality}

Let us turn to yet another traditional existence criterion, the 'Spatio-Temporality' of existing entities.

\section{Spatio-Temporality:}

Existing entities have a location in space and time.

It is obvious that a careful elaboration of this criterion is a rather delicate affair. Apparently, it is rooted in an Aristotelian view of the existence of properties, relations, etc., according to which such entities exist only if they are 'realized' or 'instantiated'. On a Platonic view, which admits of the existence of entities that are not instantiated, the validity of this criterion is much less plausible. It is also clear that materialists and certain physicalists will tend to accept this criterion more readily than their opponents.

In interpreting Spatio-Temporality, we must keep in mind that in many cases properties are predicated of entities that are themselves properties, as in 'The colour red makes bulls angry', where the property of making bulls angry is predicated of the colour red. In examining whether a given property is spatio-temporally located, we surely would not exclude it just because the referent of the nominal phrase it is ascribed to turns out to be a property itself. What we may perhaps be tempted to demand, however, is that a property exists only if judgements implying its existence must, in order to be true, be grounded in rephrasings according to which the property is realized by spatio-temporally located bearers. ${ }^{25}$

Applying this tentative conception, let us consider 'Donald's name day is on summer vacation'. It seems implausible to us that in this case any rephrasings are available according to which 'name day' and 'summer vacation' are either spatiotemporally located entities themselves, or properties realized by spatio-temporally located entities. Or consider 'French citizens have the right to form associations.' Again, we do not seem to find any accurate rephrasings according to which 'French citizens' (as opposed to ordinary people) are spatio-temporally located entities, and according to which 'the right to form associations' is realized by such entities. If our

\footnotetext{
${ }^{24}$ We also think that IFF conflict with Causal Efficacy. In section 5 we argue that certain phenomena that seem to be caused by IFF really go back to the behaviour of people, who usually succumb to the illusion that certain IFF exist.

25 It is obvious that a comprehensive study of the spatio-temporality criterion involves a whole bunch of other problems. Accordingly, as in the case of Causal Integration, our present discussion must be considered cursory and tentative.
} 
considerations go in the right direction, then adherents of (an adequate variant of) Spatio-Temporality have another reason to regard IFF with suspicion.

It is worth noting that even realists about IFF identify cases that are problematic given the acceptance of Spatio-Temporality. Drawing on observations of Smith (2003) and Thomasson (2003), John Searle famously points to facts involving electronic money and corporations. ${ }^{26}$ As an adherent of IF Realism, Searle of course does not think that the problem is fatal. To solve it, he argues that such kinds of IFF, although they are not spatio-temporally realized themselves (cf. 2010a, p. 109), always 'bottom out' in deontic facts about people that are themselves spatio-temporally realized (cf., e.g., 2007b, p. 22, 2010a, pp. 21, 108-109, 2011, p. 736). Even if the fact that I have money on my bank account is not spatio-temporally realized, its deontic consequence that I can withdraw and use this money, Searle argues, is spatio-temporally realized. It is obvious, however, that this cannot be counted as a solution of the problem at hand (even if we disregard doubts as to whether the ability or right to withdraw and use the money is in fact spatio-temporally realized). For this argument simply ignores the real problem at hand. While Searle maintains that these kinds of IFF 'bottom out' in spatio-temporal entities, he at the same time frankly admits that they are themselves not spatio-temporally located. ${ }^{27}$

\subsection{IFF and the absoluteness of existence}

Let us turn to some criteria that are not (yet) as well established as those just considered, although they are both highly intuitive and significant. To start with, there is what we call the 'Absoluteness' of existence, which implies that the existence of existing entities is not restricted in any way and that existing entities therefore do not exist (only) relative to someone or something; rather, they exist or do not, full stop. In our view, the idea of relative existence is inconsistent.

\section{Absoluteness:}

Existing entities exist absolutely, i.e., not relative to one or the other particular entity or domain. ${ }^{28}$

We must carefully separate cases where we attribute relative existence to an entity from those cases where we do so only apparently. For example, when someone says, 'For the Ancient Greeks, gods such as Dios and Hera existed', she is unlikely to mean that Dios and Hera actually existed, though (only) relative to the Ancient

\footnotetext{
26 Adopting a suggestion of Barry Smith, he calls them 'freestanding Y terms' (see 2005, p. 15, 2010a, pp. 18, 20, 2012, p. 31, 2017, p. 306), describing them as IFF that are abstract, i.e., without any physical realization; cf. Smith and Searle 2003, p. 305; Searle 2010a, pp. 20, 95, 108-109, 115, 2012, p. 32. For some discussions, see Searle (2005, pp. 15-16, 2007b, pp. 20-22, 2008, p. 454, 2010a, pp. 20, 22, 97-100, 101, 108-109, 2012, pp. 31-32), Smith and Searle (2003), Thomasson (2003, p. 273), and especially Hindriks $(2011,2012,2013)$.

27 For a critical discussion of IFF related to Causal Integration and Spatio-Temporality, see also Wahlberg (2019: section 3).

28 See Gibson (1998, pp. 6-7), who seems to be one of the few who officially endorses this criterion in written form.
} 
Greeks; rather, she probably aims at making a judgement about certain people (the Ancient Greeks), to the effect that these believed in the existence of the gods in question.

Yet there are also cases where our views and judgements really are about existence, and where existence is genuinely represented as being restricted to one or the other domain. Thus, when someone says, 'In football, handling the ball deliberately means committing a foul', then she is likely to presume (tacitly) that the act of committing a foul in football exists, and to conceive of its existence as restricted to the domain of football. Similarly, it would be quite natural to say that in Thailand, defaming the monarchy is a crime, while (tacitly) assuming that the existence of this fact (the validity of the corresponding regulations) is restricted to Thailand, or to Thai law.

In our view, it may be worth an attempt for an IF Realist to reject the intuitions we rely on. They might argue that even though the existence of IFF often or always goes back to $\mathrm{CR}$ within certain communities or institutions, our intuition that this restricts their existence accordingly is idiosyncratic. In this context, it is worth noting that even some IF Realists have the same intuition. Thus Searle, who is perhaps the most explicit defender of IF Realism, ${ }^{29}$ admits quite frankly that IFF 'exist only relative to our attitudes' (2007b, p. 13), and typically 'exist only within human institutions' (2010a, p. 10). ${ }^{30}$ His thinking that IFF enjoy relative existence does not, however, prevent him from endorsing IF Realism. Thus, he insists that IFF are 'portions of the real world' (1995, p. 1), that they 'have a real existence' (2010c, p. 231), that they are 'real features of the world' (2010b, p. 27). According to Searle, it is a mistake to believe that the kind of 'relative existence' that IFF enjoy 'implies nonreality [...] or some other dreadful low ontological [...] status', for 'this conclusion', Searle states, 'does not follow' (2007b, p. 14). As far as we can see, however, he never supports this conviction by any argument. Indeed, one of the views Searle himself insists on emphatically, that 'we live in exactly one world' (e.g., 1995, p. xi, 2010a, p. 3), is incompatible with the acceptance of relative existence: That we live in exactly one world implies, in our view, that each one of us lives, as it were, in something that comprises all the facts there are. But then, it should be impossible that there are facts

\footnotetext{
29 Anonymous reviewers pointed out to us that much of what Searle writes, particularly in his more recent publications, suggests a non-realist reading; and indeed, Baker (2019, p. 4), for example, actually takes Searle to be a non-realist. We emphatically agree that across Searle's writings, there are passages in which non-realist readings suggest themselves. We still believe that Searle should be interpreted as a realist, but nothing hinges on this: if we are wrong, we will be happy about his companionship.

30 See also Searle (1995, pp. 9-12, 27, 28, 2005, p. 3, 2010a, pp. 11, 17, 23, 174, 2014, pp. 20, 21). In 2014 , p. 21, Searle's relativism is rather explicit: 'A piece of paper is money, that is, an item of currency, only if people regard it as money and behave appropriately. I have some "Confederate currency." There was clearly a time when this was money in the early days of the Confederacy. By 1865 it was losing its validity, that is, there was a section of the southern population that continued to regard it as money and use it and accept it as money, but there was another section of the population who no longer had that attitude. Now apply the Law of Excluded Middle. Was this piece of paper money or not at that time? Granted that it is no longer money today, was it then and there money? Notice that the theory of Institutional Facts has no problem answering this. Relative to one community it was money, relative to another community it was not' (emphasis added).
} 
that exist only relative to certain people. For such facts would be facts only for these people, and not for others. And this, in turn, would amount to these people living in a world different from ours, which is quite a fantastic idea.

\subsection{IFF and the consistency of existing entities}

Our next criterion is what we call the 'Consistency' of existing entities, which can be put as follows:

\section{The Consistency Criterion:}

Existing entities are such that representations of the facts do not contradict each other.

This criterion goes back to the simple assumption that the world does not contain any inconsistencies. If the existence of a certain entity entails the existence of an inconsistency in the world, then this is a strong reason for denying the existence of this entity. The possibility of such inconsistences, however, seems to intrude into our ontology as soon as we admit of IFF. Let us turn back to the case of Peter, the king's nearest male relative. By virtue of indirect CR, he is heir apparent, because the townsmen CR that the king's nearest male relative is heir apparent. Now let us assume that people (mistakenly) take Peter's younger brother, Paul, to be the nearest male relative, and thus collectively represent Paul as heir apparent. Then, by way of direct CR, Paul is heir apparent, and Peter is not; yet by way of indirect CR, Peter is heir apparent, and Paul is not. Apparently, if we accept the existence of IFF, then we end up with inconsistencies. The underlying general problem is that when people collectively recognize a general rule of the form 'if $p$ then $q$ ', then the existence of $q$ can be generated or prevented in either of two ways, either directly or indirectly; which allows for the generation of inconsistent facts.

It may be worth emphasising in this connection that the apparent possibility of inconsistencies in the course of IFF generation plays an important role in real life. Take for example the case where a valid will is not recognized. Suppose that Peter's father, before dying, disinherited Peter in his will, thereby eliminating Peter's status of being the rightful heir of his father's heritage. Suppose further that his father's will gets lost and therefore remains unrecognized. This, in our view, is a case which is anything but far-fetched. In such a case it may well be that Peter is then declared the rightful heir and thereby made the rightful heir, even though, according to the will, he is not. ${ }^{31}$

Another problem which arises frequently is the question about the validity of marriages, viewed from different legal and cultural perspectives. Consider a couple, married at an age of 12, immigrate in the UK: are they married or not? Or what about the opposite case of a same-sex union of a couple who immigrate in a country where same-sex union is not licensed? In each of these cases, the availability

\footnotetext{
31 Legal analyses of such cases of course avoid the confession of inconsistency. Yet the possibility and reality of actual inconsistencies in such cases is obvious.
} 
of contradictory regulations enables contradictory descriptions, and apparently, the availability of those contradictory descriptions is enabled by the acceptance of the existence of IFF.

\subsection{IFF and the non-graduality of existence}

Let us turn to our last existence criterion, the 'Non-Graduality' of existence:

Non-Graduality:

Existence has no gradations. ${ }^{32}$

This criterion goes back to the highly intuitive assumption that entities cannot exist 'more or less strongly', or 'more or less definitely', or the like. Existence is, so to speak, an all-or-nothing affair.

Let us consider the case where the CR of an IF gradually decreases. Suppose that in 1740, the inhabitants of a certain village CR a certain line of stones as the borderline of their village; yet, in the course of time, the villagers forget about this gradually. In 1770, only two thirds of the villagers still CR the line of stones as the borderline, and in 1790 it is only half. Finally, in 1830, the borderline was completely forgotten. Now, what happens to the 'borderline' in the course of time? Surely its existence ceased sometime between 1770 and 1830; but at what point? It seems clear to us that there is no particular point of time, nor any criterion for determining such a point, at which the borderline can be said to have disappeared. Instead, we think it is clear, the existence of the borderline mirrors the gradual regress of its CR. ${ }^{33}$

Generally, the problem is that CR apparently admits of gradual emergence and regress. If the existence of an IF does, as it is supposed to, depend on its being CR-ed as existing, then it seems that such facts can exist gradually. But if so, then the existence of IFF systematically contradicts the Non-Graduality of Existence. ${ }^{34}$

\section{The problems of ontological projection}

In the previous section, we confronted IF Realism with six criteria of existence. In each case, we argued that the acceptance of the relevant criterion offers a more or less strong reason against IF Realism. Keeping the findings of this investigation in

\footnotetext{
32 Cf. Gibson (1998, pp. 6-7), van Inwagen (2009, pp. 482-492), and Azzouni (2011, p. 2). This is not to be confused with the claim that there are no vague entities. Although we believe that vague entities cannot exist, the present criterion is not inconsistent with believing that they can (and do).

${ }^{33}$ Of course, it is in principle possible to stipulate a 'CR threshold' arbitrarily that must be reached or exceeded for an IF to exist. However, it is also clear that such an arbitrary terminological stipulation does not lead to a solution of the problem at hand.

${ }^{34}$ In this context, it is worth noting that collective intentionality theorists are notoriously vague about what 'collective' recognition exactly amounts to. Does 'collective' recognition of $p$ mean that $p$ is the shared object of all the members' individual recognitions? Or should the term be interpreted more broadly? Our definition is unspecified in this respect. A more specific definition might have consequences for the point discussed in this section. We thank an anonymous reviewer for this suggestion.
} 
mind, let us now change our perspective on the issue slightly, focussing specifically on some of the features of Ontological Projection, the operation which is supposed to underlie the generation of IFF. We shall see that the problems of Ontological Projection largely reflect the problems of IFF, so the reasons for denying its efficacy and therefore the truth of the Projection Principle seem equally strong.

The first feature of Ontological Projection worth focussing on is the possibility of gradual emergence and decline, as mentioned at the end of the previous section. Apparently, it is due to this feature that the 'products' of Ontological Projection should be able to exist gradually. Now, if Ontological Projection is such that it is able to generate such kinds of entities, then the operation itself is in conflict with Non-Graduality.

Another feature of Ontological Projection is that whenever it generates a new entity, this entity is dependent on being CR-ed as existing, and, as explained in section 1, this involves the existence of something that is representation-dependent. So, the efficacy of Ontological Projection requires the possibility of representationdependency, which, however, violates Representation-Independence.

Perhaps the most problematic feature of Ontological Projection is the sufficiency of collectively recognizing $p$ as existing for the existence of $p$. The problems with this feature are numerous:

First, it entails the possibility to 'constitute' entities in the sense of generating them non-causally. If Ontological Projection is an operation that is able to 'constitute' entities in this sense, then of course not only its 'products' (IFF) conflict with Causal Origination but also the operation itself. ${ }^{35}$

It is worth noting that this peculiarity of Ontological Projection may raise doubts not only among determinists. Even those who do not believe in universal causal integration may prefer to reject the kind of 'constitution' under consideration. To illustrate this point, let us compare the relation between CR and IFF with the relation between brain and mind. As with CR and IFF, one could argue that certain brain states generate (certain states of) the mind, even though the relation is not one of causation. In this case, however, it is difficult to argue that if mind is not caused by corresponding brain states, it does not exist, for each one of us has exceedingly strong evidence that at least one's own mind exists, due to the special kind of direct access everyone has to their own minds. The case of IFF is quite different. Here we do not only lack this special kind of access; we seem to lack any kind of direct access. Thus, even for an indeterminist, this kind of constitution may be doubtful.

The fact that the kind of constitution under consideration seems to exclude the possibility of any direct access to its 'products' raises the problem of how one could conceivably have knowledge about IFF. When Searle was confronted with this problem, he argued that even though IFF are not 'directly observable' we can ascertain their existence 'indirectly', just as we can indirectly ascertain the existence of black

\footnotetext{
35 Our suggestion that 'non-causal generation' in the sense under consideration is ontologically suspicious is not new. In the debate on abstract artifacts, for example, some authors also express doubts concerning the alleged possibility to 'create' things non-causally. See Irmak (2020), who refers to Dodd (2000), Brock (2010), French and Vickers (2011) as well as Mag Uidhir (2012).
} 
holes and subatomic particles (cf. 2006, p. 117). In our view, this suggestion fails, for black holes and subatomic particles seem to differ from IFF in a crucial respect: they are supposed to be causally efficacious, while IFF do not seem to play any causal role at all, as we shall argue in the following section.

Another problem is that if the CR of $p$ is sufficient for the existence of $p$, then people seem in principle to be able to generate entities that are not located in space and time. Nothing, in principle, seems to prevent them from collectively recognizing and thereby generating the existence of facts about Cartesian souls, for example. Moreover, they seem in principle to be able to generate facts that are inconsistent with brute facts. For example, in earlier times people CR-ed that hell is located underground and inhabited by the devil. Today the leading opinion is that, as a matter of (brute) fact, hell and the devil do not (and never did) exist. That hell is inhabited by the devil obviously cannot be accommodated with this. Yet if Ontological Projection were effective, it would be a fact.

An obvious objection at this point is that the efficacy of Ontological Projection is not unrestricted. John Searle, for example, suggests that its efficacy is restricted to the generation of facts that does not involve the alteration of given or the generation of new 'brute' (or 'physical') facts (see 1995, pp. 10, 57, 96, 2006, p. 115f., 2010a, pp. 89, 100). Thus, to cite some of Searle's own examples, we cannot create light (cf. 2010a, p. 100) or fry eggs (cf. 1983, p. 176) or make it rain by means of CR. For those who doubt the effectiveness of Ontological Projection from the outset, however, this seems to call for an explanation. Why exactly can't we create light, fry eggs and make it rain by means of collective recognition?

Indeed, this is what Searle himself calls a 'miracle' in an unpublished manuscript ${ }^{36}$ containing a version of a reply to Colin McGinn: 'Here is the "miracle" [...] of human institutional reality', Searle begins. 'If we all get together and agree that it is raining, that fact by itself will not make it rain. But if we all get together and agree in a certain way that such and such is money then the stuff in question is money'. Searle goes on to say that he provides an extensive explanation of this miracle in Making the Social World. To our best knowledge, however, he does not. We conjecture that what he has in mind here is his reference to the notions of 'declaration' and 'direction of fit'. In Making the Social World, he claims that all IFF are 'created and maintained in existence by (representations that have the same logical form as) [...] Declarations' (2010a, p. 13). Having the same logical form as Declarations, according to Searle, means having 'the double direction of fit' (2010c, p. 228). And saying that representations have the 'double direction of fit' amounts to saying that they are representations that 'make it the case that something exists by virtue of representing it as existing' (cf. 2012, p. 35; cf. also 2008, pp. 452, 459, 2010a, p. 86, 2010b, p. 35). Yet notice that the reference to such notions as 'declaration' and 'direction of fit' is not explanatory in any substantial sense. The reference to them does not clarify the actual mystery: that we are (supposed to be) able to make something the

\footnotetext{
${ }^{36}$ It was originally available under http://socrates.berkeley.edu/ jsearle/articles.html. Unfortunately, the site has been shut down in the meantime.
} 
case simply by virtue of (collectively recognizing or collectively) representing it as existing.

Something similar can be observed in an earlier work of Searle: In Intentionality, he suggests that we cannot do such things ' $[\mathrm{b}]$ ecause the capacities of representation are here exceeded. A supernatural being could do this because such a being could intentionally bring states of affairs about solely by representing them as having been brought about. We can't do that' (1983, p. 176). Importantly, even though the use of 'because' indicates an explanation, the statement that the capacities of representations are there exceeded does not explain that phenomenon in any meaningful way. Sceptics like us would seem justified in continuing to ask, 'But why are the capacities of representation there exceeded?' To our best knowledge, Searle never offers a meaningful answer to such a question, and we doubt he could.

We would also like to emphasize that even if the efficacy of Ontological Projection could be reasonably construed as being restricted in the suggested way, the problems would not end here. For even then, people would seem to be able to generate IFF that are inconsistent with each other, as explained in the previous section. Remember the case of Peter and Paul. Due to direct CR, Paul is heir apparent, and Peter is not. But due to indirect CR, Peter is heir apparent, and Paul is not. These facts are mutually incompatible; but when we accept the efficacy of Ontological Projection (even in its restricted variant), we must accept the existence of these facts. It is clear that another restriction to the effect that people cannot generate mutually inconsistent IFF would be ad hoc.

To conclude, the problems that would be entailed by Ontological Projection, if it were efficacious, largely reflect the problems we encountered in the examination of IFF. We therefore believe that the reasons for denying the efficacy of Ontological Projection and thus the truth of the Projection Principle are equally strong.

\section{An explanatory gap?}

For most people who presume (as we do) that facts such as the fact that certain paper bills have monetary value, that Vladimir Putin is the president of Russia, and that Prince Philip is the husband of Queen Elizabeth II, are IFF, the idea that IFF really do not exist seems bewildering or even absurd. Most people who are confronted by this idea are not convinced at one stroke. A very common type of response goes along the following lines.

It is hard to deny that the ways we behave largely 'mirror', 'are suited to', the assumption that IFF exist. When Jill is the leader of a certain tribe, people will, for example, treat her with respect, consider and follow her orders, reward her with presents, and so on. And when certain pieces of paper are five-pound notes, then people will use them accordingly, by changing two of them for a ten-pound note, by giving a pint of beer in exchange for one of them, and so on. So, there is a certain rather peculiar 'correspondence' between the existence of IFF and people's behaviour (it is argued), and this must surely be 
explained somehow. Yet without the assumption that IFF exist, we seem to be at a loss. Without IF Realism, there is an obvious explanatory gap.

We admit that this line of argument has some intuitive appeal, even to us. And yet, we believe that the argument fails; indeed, we do not think there is any explanatory gap, or at least any obvious gap. To start with, we should like to introduce a variant of the so-called 'Thomas Theorem'. W.I. Thomas \& D.S. Thomas famously argued that '[i]f men define situations as real, then they are real in their consequences' (1928, p. 572). Our variant goes as follows:

\section{The Thomas* Theorem:}

If people CR that $p$, then they largely behave as if $p$ was the case (regardless of whether $p$ is actually the case or not). ${ }^{37}$

We think it is plausible enough that this variant of the Thomas Theorem holds. When the inhabitants of a village represent a certain line of stones as the borderline of their village, then they will largely think, feel, evaluate and act as if that line of stones $i s$ the borderline of their village-regardless of whether the line of stones actually is a borderline or not, and regardless of whether in general, borderlines exist or not. Also, when handling the ball deliberately is CR-ed as being a foul in football, then football players will largely think, feel, evaluate and act as if it is a foul-regardless of whether it actually is a foul or not, and regardless of whether in general, there are such entities as 'fouls' in the world. ${ }^{38}$

If we assume that the Thomas* Theorem holds, then we can expect there to be a large 'correspondence' between objects of CR in a group on the one hand, and the behaviour of the members of the relevant group on the other, without having to assume that those IFF really exist. With reference to the Thomas* Theorem, nonrealism about IFF can easily explain such correspondence. ${ }^{39}$

\footnotetext{
${ }^{37}$ Read 'behave' in a wide sense in which it covers not merely outward behaviour, such as actions, but also inward behaviour, such as believing and feeling. Obviously, our variant of the Thomas Theorem is rather much a rule of thumb, subject to considerable vagueness, particularly with respect to the word 'largely' and the phrase 'behave as if'. This corresponds to the fact that the discussion of the present issue is still in its infancy.

${ }^{38}$ Apparently, there is more than one reason for believing why something like the Thomas* Theorem holds. In the early modern period in Europe, for example, it was CR-ed that god exists, and people behaved rather much in accordance with this. Yet of course not all people actually believed in god's existence. Certainly, many did, and behaved accordingly. Yet surely, some did not, but still behaved rather much as if they did. One reason for this may be that often people tend to behave just like others do. Another is that atheism was socially banned and subject to serious sanctions, including legal consequences. For another example, consider the monetary value of bank notes. We ourselves do not believe that the monetary value of bank notes exists, yet of course we behave as if it did, because doing so spares us a lot of trouble. While the existence of monetary value is a mere illusion (in our view), it is an extremely serviceable one.

39 The Thomas* Theorem is also able to explain what Searle calls 'the glue that holds society together' (2010a, p. 9). Searle argues that IFF are, or provide, this glue 'because they carry the special type of deontology that makes society possible' (2008, p. 452; cf. 2005, pp. 9-10, 2007b, p. 15, 2008, pp. 449459,2010 b, p. 36, 2013, pp. 423-424, 2014, p. 20). Possibly, Searle intends this to support his IF Realism, by representing society's cohesion as an explanandum, and IF Realism as its explanation. A careful reading of Searle's own arguments indicates, however, that IF Realism is explanatorily dispensable, given (something like) the Thomas* Theorem. 'What is the power of the glue?", Searle once asks, and
} 
It is worth noting that what we are to explain is indeed only a rough correspondence between (purported) IFF and our behaviour, because the correspondence really is not strict. When Columbus sailed westwards to get to India, this did not correspond to the IF that the earth is flat, and when some plotters try to subvert Peter, the legitimate heir apparent, their behaviour does not correspond to the IF that Peter is heir apparent.

One might object that we focus too much on people's behaviour and disregard other evidence for IFF. This objection depends on the presumption that there actually are traces of IFF in the world apart from people's behaviour (and its consequences). However, as soon as you try to give examples, you will find what is surprising for many: Apart from people's behaviour (and its consequences), there really seem to be no traces of IFF in the world. All the facts in the world that appear to indicate the existence of IFF are either generated by, or finally go back to, the behaviour of people who either CR, or believe, or pretend to believe, or are forced to act according to the view, that the relevant IFF exist. For instance, the existence of bank notes may be viewed as a trace of the IF that monetary value exists, but can in fact be explained quite as well by the view that certain people made them and use them who either believe, or pretend to believe, or find it profitable to act as if, or are forced to act according to the assumption that these notes have monetary value. To generalize, we think that there is no trace of any IF in the world that cannot be easily and convincingly be led back to people's behaviour.

Admittedly, these quick and partly speculative arguments for our point of view are far from conclusive. It is worth working much more on the phenomenology of IFF. However, what we claim to have achieved is to defeat the view that the rejection of IF Realism leaves an obvious explanatory gap. If there is such a gap, it is far from obvious. So, the objection fails, at least in the less subtle form that we have considered.

\section{Summary}

After a brief defence of the method of existence criteria against recent doubts, we confronted IF Realism with six existence criteria, three established and three less so but highly intuitive. In each case the investigation provided, as we believe, reasons for doubting the existence of IFF. Keeping these findings in mind, we then directed our focus more immediately on Ontological Projection, the operation which

\footnotetext{
Footnote 39 (continued)

then argues: 'The answer is that to the extent that people recognize the validity of Status Functions, they recognize them as having a deontic status, and for that reason, they recognize them as giving reasons for action which are independent of their immediate inclinations' (2010b, p. 36, emphasis added); and elsewhere he adds: 'The person who recognizes that someone else has a valid claim to a piece of private property $[\ldots]$ recognizes that he/she has a reason for action in certain ways, independently of his or her desires' (Searle 2013, p. 424, emphasis added). Here, Searle himself seems to give an explanation of 'the glue' that goes without IF Realism: His exposition suggests that all we need for the existence of such a thing as 'the glue' are certain representations of individuals (together with other psychological facts).
} 
is supposed to achieve the generation of IFF. We argued that the problems raised by Ontological Projection closely correspond to the problems we encountered in the examination of IFF, and therefore suggested that the efficacy of Ontological Projection should be denied. Finally, we considered an argument in defence of IF Realism, namely that non-realism about IFF faces an obvious explanatory gap. We rejected this argument with reference to a variant of the 'Thomas Theorem'. In the light of these findings, we think, it is reasonable enough to abandon IF Realism. Admittedly, to deny the existence of IFF in real life usually leads to nothing but bother. Furthermore, collectively recognizing IFF as existing is probably one of the most fruitful devices that societies have at their disposal. Still, despite its usefulness, the belief that some or all IFF really exist is just an illusion.

Funding Open Access funding enabled and organized by Projekt DEAL.

\section{Compliance with ethical standards}

Conflict of interest The authors declare that they have no conflict of interest.

Open Access This article is licensed under a Creative Commons Attribution 4.0 International License, which permits use, sharing, adaptation, distribution and reproduction in any medium or format, as long as you give appropriate credit to the original author(s) and the source, provide a link to the Creative Commons licence, and indicate if changes were made. The images or other third party material in this article are included in the article's Creative Commons licence, unless indicated otherwise in a credit line to the material. If material is not included in the article's Creative Commons licence and your intended use is not permitted by statutory regulation or exceeds the permitted use, you will need to obtain permission directly from the copyright holder. To view a copy of this licence, visit http://creativecommons.org/licen ses/by/4.0/.

\section{References}

Anscombe, G. E. M. (1958). On brute facts. Analysis, 18(3), 69-72.

Azzouni, J. (1998). On 'on what there is.' Pacific Philosophical Quarterly, 79, 1-18.

Azzouni, J. (2004). Deflating existential consequence. A case for nominalism. Oxford: Oxford University Press.

Azzouni, J. (2010). Talking about nothing. Numbers, hallucinations, and fictions. Oxford: Oxford University Press.

Azzouni, J. (2011). Can science change our notion of existence? http://www.protosociology.de/Downl oad/Azzouni-Existence.pdf. Accessed 26 November 2019.

Baker, L. R. (2019). Just what is social ontology? Journal of Social Ontology, 5(1), 1-12.

Brock, S. (2010). The case against creationism about fictional characters. Philosophical Review, 119(3), $337-364$.

Dodd, J. (2000). Musical works as eternal types. British Journal of Aesthetics, 40(4), 424-440.

Epstein, B. (2014). Social objects without intentions. In A. Konzelmann Ziv \& H. B. Schmid (Eds.), Contributions to social ontology (Vol. 2, pp. 53-68). Dordrecht: Springer.

Epstein, B. (2014). How many kinds of glue hold the social world together? In M. Gallotti \& J. Michael (Eds.), Perspectives on social ontology and social cognition (Vol. 4, pp. 41-44). Dordrecht: Springer.

Epstein, B. (2015). The ant trap. Rebuilding the foundations of the social sciences. Oxford: Oxford University Press. 
French, S., \& Vickers, P. (2011). Are there no things that are scientific theories? British Journal for the Philosophy of Science, 62(4), 771-804.

Gibson, Q. (1998). The existence principle. Dordrecht: Kluwer Academic Publishers.

Guala, F. (2014). On the nature of social kinds. In M. Gallotti \& J. Michael (Eds.), Perspectives on social ontology and social cognition (pp. 57-68). Dordrecht: Springer.

Guala, F. (2016). Understanding institutions: The science and philosophy of living together. Princeton: Princeton University Press.

Guala, F., \& Hindriks, F. (2015). A unified social ontology. The Philosophical Quarterly, 65(259), 177-201.

Hindriks, F. (2011). Restructuring Searle's 'Making the Social World.' Philosophy of the Social Sciences, 43(3), 373-389.

Hindriks, F. (2012). But where is the university? Dialectica, 66(1), 93-113.

Hindriks, F. (2013). The location problem in social ontology. Synthese, 190, 413-437.

Holweger, M. (2020). The Simple Nature of Institutional Facts. Unpublished manuscript.

Irmak, N. (2020). The problem of creation and abstract artifacts. Synthese. https://doi.org/10.1007/s1122 9-020-02672-6.

Kim, J. (2005). Physicalism, or something near enough. Princeton: Princeton University Press.

Mag Uidhir, C. (2012). Introduction: Art, metaphysics, and the paradox of standards. In C. M. Uidhir (Ed.), Art and abstract objects (pp. 1-26). Oxford: Oxford University Press.

Mäkkelä, P., \& Ylikoski, P. (2003). Others will do it. In M. Sintonen, P. Ylikoski, \& K. Miller (Eds.), Essays in the philosophy of the social sciences (pp. 259-268). Dordrecht: Kluwer.

Raley, Y. (2004). On ontology. Unpublished dissertation.

Searle, J. R. (1964). How to derive 'Ought' from 'Is.' Philosophical Review, 73(1), 43-58.

Searle, J. R. (1983). Intentionality. An essay in the philosophy of mind. Cambridge: Cambridge University Press.

Searle, J. R. (1995). The construction of social reality. New York: Free Press.

Searle, J. R. (1997). Responses to critics of the construction of social reality. Philosophy and Phenomenological Research, 57(2), 449-458.

Searle, J. R. (2005). What is an institution? Journal of Institutional Economics, 1(1), 1-22.

Searle, J. R. (2006). Reality and relativism. Shweder on a which? Hunt. Anthropological Theory, 6(1), 112-121.

Searle, J. R. (2007a). Social ontology and the philosophy of society. In E. Margolis \& S. Laurence (Eds.), Creations of the mind (pp. 3-17). Oxford: Oxford University Press.

Searle, J. R. (2007b). Social ontology: The problem and steps towards a solution. In S. L. Tsohatzidis (Ed.), Intentional acts and institutional facts (pp. 11-28). Dordrecht: Springer.

Searle, J. R. (2007c). Freedom and neurobiology. Reflections on free will, language, and political power. New York: Columbia University Press.

Searle, J. R. (2008). Language and social ontology. Theory and Society, 37(5), 443-459.

Searle, J. R. (2010a). Making the social world. The structure of human civilization. Oxford: Oxford University Press.

Searle, J. R. (2010b). Replies. In D. Franken, J. G. Michel, \& A. Karakus (Eds.), Thinking about the real world (pp. 201-236). Frankfurt a. M.: Ontos Verlag.

Searle, J. R. (2010c). The basic reality and the human reality. In D. Franken, J. G. Michel, \& A. Karakus (Eds.), Thinking about the real world (pp. 19-44). Frankfurt a. M.: Ontos Verlag.

Searle, J. R. (2011). Replies. Analysis, 71(4), 733-741.

Searle, J. R. (2012). Human social reality and language. Phenomenology and Mind, 2, 27-39.

Searle, J. R. (2013). Reconciling the basic reality and the human reality-Post Kantian themes. In S. Bacin, A. Ferrarin, C. La Rocca, \& M. Ruffing (Eds.), Kant und die Philosophie in weltbürgerlicher Absicht. Akten des XI.. Kant-Kongresses 2010 (pp. 407-430). Berlin: Walter de Gruyter.

Searle, J. R. (2014). Are there social objects? In M. Gallotti \& J. Michael (Eds.), Perspectives on social ontology and social cognition (pp. 17-26). Dordrecht: Springer.

Searle, J. R. (2017). Status functions. In M. Jankovic \& K. Ludwig (Eds.), The Routledge handbook of collective intentionality (pp. 300-309). London: Routledge.

Smit, J. P., Buekens, F., \& du Plessis, S. (2014). Developing the incentivized action view of institutional reality. Synthese, 191, 1813-1830.

Smith, B. (2003). John Searle: From speech acts to social reality. In B. Smith (Ed.), John Searle (pp. 1-33). Cambridge: Cambridge University Press. 
Smith, B., \& Searle, J. R. (2003). The construction of social reality: An exchange. The American Journal of Economics and Sociology, 62(1), 285-309.

Thomasson, A. (2003). Foundations for a social ontology. Protosociology. An International Journal of Interdisciplinary Research, 18/19, 269-290.

Thomasson, A. (2008). Existence questions. Philosophical Studies, 141, 63-78.

Thomasson, A. (2015). Ontology made easy. Oxford: Oxford University Press.

Thomas, D. S., \& Thomas, W. I. (1928). The child in America: Behavior problems and programs. New York: Knopf.

van Inwagen, P. (2009). Being, existence, ontological commitment. In D. J. Chalmers, D. Manley, \& R. Wasserman (Eds.), Metametaphysics. New essays on the foundations of ontology (pp. 472-506). Oxford: Oxford University Press.

Wahlberg, T. H. (2019). The creation of institutional reality, special theory of relativity, and mere Cambridge change. Synthese. https://doi.org/10.1007/s11229-019-02435-y.

Publisher's Note Springer Nature remains neutral with regard to jurisdictional claims in published maps and institutional affiliations. 